\title{
Comparison of structural characteristics and combustibility analysis about hydrochar and pyrochar
}

\author{
Chunchao Huang ${ }^{1}$ (I) $\cdot$ Chunmei Yu ${ }^{1} \cdot$ Guangwei Wang ${ }^{1} \cdot$ Jianliang Zhang ${ }^{1} \cdot$ Xiaojun Ning $^{1,2} \cdot$ Chuan Wang $^{3,4}$
}

Received: 30 April 2021 / Accepted: 14 January 2022 / Published online: 28 February 2022

(c) Akadémiai Kiadó, Budapest, Hungary 2022

\begin{abstract}
The structure characteristics and combustibility of pyrochar and hydrochar were compared using scanning electron microscopy, nitrogen adsorption, Fourier transform infrared spectrum, Raman spectrum and thermogravimetry. The random pore model was applied to analyze the combustion process of chars. With the temperature increasing, analysis of physical structure revealed that the pore structure of hydrochar was more developed than that of pyrochar. Meanwhile, the hydrothermal process had an advantage over pyrolysis in terms of removing oxygen-containing functional groups and improving the coal rank, mainly attributed to the existence of subcritical water. In addition, the high determination coefficient of random pore model indicated that the model could accurately obtain the kinetic parameters. The activation energies calculated of hydrochars were higher than that of pyrochars, indicating that carbon in hydrochar had a more structural stability. The pyrochar obtained after $220{ }^{\circ} \mathrm{C}$ was less combustible than hydrochar due to its severe pore collapse during the combustion process.
\end{abstract}

Keywords Hydrothermal modification $\cdot$ Pyrolysis modification $\cdot$ Pyrochar $\cdot$ Hydrochar $\cdot$ Combustion

\section{Introduction}

According to the forecast of World Steel Association, global steel demand will contract by $-2.4 \%$ to 1725.1 Mt due to the influence of the COVID-19 pandemic; then recover to 1795.1 Mt in 2021, an increase of $4.1 \%$ year-on-year [1]. It is also undeniable that the pioneering recovery in China's economy will mitigate the decline in global steel demand this year. The blast furnace and basic oxygen furnace (BF$\mathrm{BOF}$ ) process dominates the steel industry in China, with concerning $64 \%$ of the crude steel production, a share that has fallen only slightly over the previous our years [2]. As

Guangwei Wang

guangwei_wang@ustb.edu.cn

$\triangle$ Chuan Wang

Chuan.Wang@swerim.se

1 State Key Laboratory of Advanced Metallurgy, University of Science and Technology Beijing, Beijing 100083, China

2 GuanZhuang Campus, University of Science and Technology Beijing, Beijing 100083, China

3 Swerim AB, 97125 Luleå, Sweden

4 Thermal and Flow Engineering Laboratory, Åbo Akademi University, 20500 Åbo, Finland known to all, coke is an indispensable raw material for the normal operation of blast furnaces (BF). However, the coking process generates large amounts of toxic chemicals [3], as well as dust and sewage. Aiming to reduce the amount of coke used, the technology named pulverized coal injection (PCI) has developed rapidly [4, 5]. In recent years of China, the feedstock for PCI is mainly the blend of anthracite and bituminous coal. Unfortunately, the recoverable reserves of anthracite in China are only $1.131 \times 10^{4} \mathrm{Mt}$, with a quarter of low-rank coal [6]. To mitigate the increasing cost of anthracite, some China steelmakers begin to use pyrochar as a raw material for PCI. As an example, Baosteel has been blending $30 \%$ of its coal with pyrochar since 2019 .

It is undeniable that the pyrolysis treatment plays a crucial role in the application of low-rank coal and biomass [7-11]. However, similarity to the coking process, the pollutants generated during coal pyrolysis cannot be ignored. The pyrolysis process involves a variety of chemicals that contribute to the greenhouse effect and atmospheric pollution. It is not possible to limit emissions or control all of them; only a few key pollutants can be selected for control. Table 1 presents data on the assessment of potential toxicity of contaminants $[12,13]$. It demonstrates that these lethal chemical substances are all far beyond the safety standard for plant, same for humans. In addition, the pyrolysis process 
Table 1 Main pollutants from the process of coal pyrolysis

\begin{tabular}{llll}
\hline Emission types & $\begin{array}{l}\text { Effluent } \\
\text { standard/ } \\
\text { PPM }\end{array}$ & $\begin{array}{l}\text { Effluent } \\
\text { concentration/ } \\
\text { PPM }\end{array}$ & $\begin{array}{l}\text { Phytotoxicity to plant } \\
\text { within effective con- } \\
\text { centration/PPM }\end{array}$ \\
\hline $\mathrm{CS}_{2}$ & 90 & $200-10,000$ & 0.3 \\
$\mathrm{H}_{2} \mathrm{~S}$ & 10 & & $0.3-1000$ \\
$\mathrm{NH}_{3}$ & 25 & & $20-50$ \\
$\mathrm{HCN}$ & 10 & & 1000 \\
$\mathrm{BTX}$ & & $10-2000$ & 10,000 \\
\hline
\end{tabular}

BTX: benzene, toluene and xylene

requires an uninterrupted flux of nitrogen, which can lead to dilution of the pyrolysis gas and make it difficult to reuse.

At the early twentieth century, the concept of hydrothermal carbonization (HTC) was introduced by Bergius during the research process of cellulose upgrading [14]. In relation to the traditional pyrolysis, HTC is a promising and technically attractive technology to upgrade low-rank coal, biomass and waste plastics $[15,16]$. It was reported that HTC with closed circumstance not only had the advantages on energy saving and environment protection, but also mild reaction condition [17]. However, the substantial amount of poisonous organic wastewater was inevitable in the applications of HTC [18-20]. HTC's effluent treatment was inevitable, but we should not overshadow some genuine achievements [21]. Further, the upgrading technology for low-rank coal should not only be limited to PCI, but also related to clean coal technology (CCT). In fact, the practical application of biochar or hydrochar was brought to the focus of attention in recent years [15, 22-24]. Wang et al. [15] argued that the optimum operation parameters for HTC were $280{ }^{\circ} \mathrm{C}$ and $60 \mathrm{~min}$, while studying the upgrading process of maize straw. The effect of experimental conditions on the pelletization characteristics of hydrochar was widely investigated by Zhang et al. [25]. The result further demonstrated the feasibility of hydrochar as an available clean resource. There were other studies focused on hydrochar reactivity. Wei et al. [26] analyzed the co-gasification reactivity of the mixture of bituminous coal and biomass hydrochar, and the result showed that the synergistic effect existed only in the co-gasification period. Meanwhile, several studies were performed HTC technology on low-rank coal upgrading. Many research results pointed to the fact that HTC was effective in removing oxygen-containing functional groups [27-29]. Under the action of high-temperature water in HTC, some organic structures with poor thermal stability may undergo both hydrolysis and pyrolysis [30]. The catabolite of HTC may be quite different from the pure pyrolysis process. Predictably, HTC would have an ample opportunity to diversify its raw materials that could be handled beyond traditional pyrolysis process due to its deep conversion in coal upgrading.
The comparison of pyrolysis and HTC also was studied by some scholars. Catalina et al. [31] studied the effects of different agricultural biomass components on the structure of char obtained during pyrolysis and HTC. Céline et al. [32] focused on comparing the effect of pyrolysis and hydrothermal liquefaction (HTL) of biomass and showed that HTL was able to obtain more bio-oil at a lower temperature. However, most of the studies were on biomass. It was well known that coal had a biomass origin, especially low-rank coal, which had similar properties to biomass. Therefore, it was equally important to compare and analyze pyrolysis upgrading and hydrothermal upgrading of low-rank coals.

The aim of this paper was to compare the structure features of pyrochar and hydrochar and the links with combustion properties. Firstly, images of the surface topography were observed using scanning electron microscopy (SEM). The physical properties were characterized in conjunction with the result of nitrogen adsorption. Meanwhile, Fourier transform infrared spectroscopy (FTIR) and Raman spectroscopy were carried out to analysis the functional groups and carbon structure, respectively. Secondly, the combustibility of char samples was studied with the non-isothermal thermogravimetry. To figure out the combustive differences between pyrochar and hydrochar, the random pore model (RPM) was employed to obtain the kinetic parameters. The assessment results could offer a more clearly understanding for the efficient utilization of low-rank coal.

\section{Material and experimental methods}

\section{Material preparation}

The low-rank raw coal, denoted as RC in this paper, was collected from a colliery in inner Mongolia, China. Because of the large amounts of moisture, the obtained RC sample was pretreatment for over-drying first: in a $105^{\circ} \mathrm{C}$ drying oven for $4 \mathrm{~h}$. Then, the dried RC was crushed and sieved to 0.6-5.0 $\mathrm{mm}$ for upgrading experiment. Besides, RC needed to be screened for particles smaller than $74 \mu \mathrm{m}$, as one of the materials for further tests. The preparation of pyrochar was performed in a quartz tube furnace (SK13-12) with an inert atmosphere $\left(99.999 \% \mathrm{~N}_{2}\right) .30 \pm 0.01 \mathrm{~g} \mathrm{RC}$ was weighed each time, followed by placing it at the furnace. Under the same premise of heating rate of $10{ }^{\circ} \mathrm{C} \cdot \mathrm{min}^{-1}$, nitrogen flow of 5 $\mathrm{L} \cdot \mathrm{min}^{-1}$ and holding time of $120 \mathrm{~min}$, the final temperature was set to $220,260,300$ and $340{ }^{\circ} \mathrm{C}$. The obtained pyrochars were marked as P-220, P-260, P-300 and P-340, respectively.

The mass of RC was kept consistent with the pyrolysis experiment. HTC was carried out at a high-pressure reactor (HT-250FC-I-F001) with a total capacity of $250 \mathrm{~mL}$, design pressure of $27 \mathrm{MPa}$ and design temperature of $400{ }^{\circ} \mathrm{C}$. The additional $120 \mathrm{~mL}$ of deionized water was 
poured into the reactor as a solvent. To create an inert atmosphere inside the vessel, the same high-purity nitrogen as for pyrolysis was injected to expel air. In particular, the magnetic drive application in this container instead of traditional mechanical stirring has been used, at the speed of $300 \mathrm{rpm}$. To obtain the comparable char products, the control parameters of HTC must remain consistent with pyrolysis, such as the heating rate, holding time and final temperature. The HTC reactor was naturally cooled to room temperature followed the end of reaction. After separating the solid-liquid by vacuum filtration, the solid char was dried at $105{ }^{\circ} \mathrm{C}$ for $4 \mathrm{~h}$. Similar to pyrolysis samples, the obtained hydrochars were denoted by H-220, $\mathrm{H}-260, \mathrm{H}-300$ and $\mathrm{H}-340$, respectively.

In order to meet the requirement of PCI, all obtained chars were broken using a tray-type gyratory crusher. The crushed particle was ground into the size of less than $74 \mu \mathrm{m}$ for further detection. Additionally, the proximate and ultimate analysis were performed according to Chinese standard GB-T212 and GB-T476, respectively [33]. The higher heating value (HHV) and mass yield (MY) were calculated according to Eqs. (1) and (2) [14, 34, 35].

$$
\begin{aligned}
\mathrm{HHV}= & 0.3491 \mathrm{C}+1.1783 \mathrm{H}+0.1005 \mathrm{~S} \\
& -0.1034 \mathrm{O}-0.0151 \mathrm{~N}-0.0211 \mathrm{~A}
\end{aligned}
$$

wherein $\mathrm{C}, \mathrm{H}, \mathrm{N}, \mathrm{O}, \mathrm{S}$ and $\mathrm{A}$ are alternative symbols for mass percent of carbon, hydrogen, nitrogen, oxygen, sulfur and ash in sample, respectively.

$\mathrm{MY}=\mathrm{MH} / \mathrm{MR}$

where $\mathrm{MH}$ and $\mathrm{MR}$ are abbreviations for the mass of char and mass of RC, respectively (Table 2).

\section{Sample characterization}

\section{Physical characteristics}

The surface morphology was observed by using a scanning electron microscope (SEM). The pore structures were revealed by the method of nitrogen adsorption. Since the grain size had been rigorously screened, it was sufficient to analyze the specific surface area of particles with nitrogen adsorption alone.

\section{Chemical characteristics}

The chemical properties of the samples were analyzed using FTIR spectra and Raman spectra. The bands assignment of FTIR spectra [36] and Raman spectra [37] is presented in Tables 3 and 4, respectively.

\section{Thermogravimetric analysis}

In this paper, the combustion test was performed with the method of thermogravimetric analysis (TGA). The reaction atmosphere was air with the flow rate of $60 \mathrm{~mL} \cdot \mathrm{min}^{-1}$. Approximately $5 \mathrm{mg}$ sample was weighted and then placed at a size of $5 \times 2 \mathrm{~mm}$ corundum crucible. Under the three different heating rates $\left(5{ }^{\circ} \mathrm{C} \cdot \mathrm{min}^{-1}, 10^{\circ} \mathrm{C} \cdot \mathrm{min}^{-1}\right.$ and $20^{\circ} \mathrm{C} \cdot \mathrm{min}^{-1}$ ), the thermogravimetric analyzer (HCT-4) was set to record from room temperature to $700{ }^{\circ} \mathrm{C}$. To reduce errors and improve data precision, each experiment was repeated three times. The combustion conversion rate $(x)$ could be calculated as the following formula:

$$
x=\frac{m_{0}-m_{\mathrm{t}}}{m_{0}-m_{\mathrm{ash}}}
$$

\begin{tabular}{|c|c|c|c|c|c|c|c|c|c|c|}
\hline \multirow[t]{2}{*}{ Sample } & \multicolumn{3}{|c|}{$\begin{array}{l}\text { Proximate analysis/ } \\
\text { mass } \%\end{array}$} & \multicolumn{5}{|c|}{ Ultimate analysis/mass \% } & \multirow[t]{2}{*}{$\begin{array}{l}\text { Atomic ratio of } \\
(\mathrm{H}+\mathrm{O}) \text { to } \mathrm{C}\end{array}$} & \multirow[t]{2}{*}{$\mathrm{HHV} / \mathrm{MJ} \cdot \mathrm{kg}^{-1}$} \\
\hline & $\mathrm{FC}_{\mathrm{d}}{ }^{\mathrm{a}}$ & $A_{\mathrm{d}}$ & $V_{\mathrm{d}}$ & $C_{\mathrm{d}}$ & $H_{\mathrm{d}}$ & $O_{\mathrm{d}}{ }^{\mathrm{a}}$ & $N_{\mathrm{d}}$ & $S_{\mathrm{d}}$ & & \\
\hline $\mathrm{RC}$ & 59.02 & 9.79 & 31.18 & 66.06 & 4.25 & 18.01 & 0.72 & 0.47 & 0.98 & 26.04 \\
\hline P-220 & 59.08 & 10.49 & 30.53 & 67.33 & 4.01 & 17.60 & 0.89 & 0.50 & 0.91 & 26.23 \\
\hline P-260 & 59.57 & 10.35 & 30.08 & 70.15 & 3.94 & 14.27 & 0.87 & 0.42 & 0.83 & 27.47 \\
\hline P-300 & 59.93 & 9.86 & 29.77 & 71.79 & 3.84 & 13.22 & 0.92 & 0.37 & 0.78 & 28.03 \\
\hline P-340 & 60.75 & 10.32 & 28.33 & 73.87 & 3.57 & 10.96 & 0.95 & 0.33 & 0.69 & 28.66 \\
\hline H-220 & 60.13 & 7.79 & 32.08 & 69.06 & 3.79 & 17.93 & 0.79 & 0.64 & 0.85 & 26.61 \\
\hline $\mathrm{H}-260$ & 63.51 & 6.56 & 29.93 & 71.86 & 3.86 & 16.62 & 0.73 & 0.37 & 0.82 & 27.80 \\
\hline H-300 & 66.49 & 5.35 & 28.16 & 74.14 & 3.59 & 15.79 & 0.77 & 0.36 & 0.74 & 28.39 \\
\hline H-340 & 68.06 & 5.60 & 26.56 & 76.41 & 3.53 & 13.29 & 0.76 & 0.41 & 0.68 & 29.37 \\
\hline
\end{tabular}

Table 2 The proximate and ultimate analysis of samples
FC Fixed carbon; $A$ ash; $V$ volatile matter; subscript d dry basis

${ }^{\mathrm{a}}$ Calculated by difference 
Table 3 Bands assignment of FTIR absorptive peaks $\left(500-4000 \mathrm{~cm}^{-1}\right)$

\begin{tabular}{|c|c|c|c|}
\hline Fluctuation range & Types & Wavenumber/cm ${ }^{-1}$ & Vibration form and structure of absorption peak \\
\hline \multirow[t]{6}{*}{$3600-3000$} & \multirow[t]{6}{*}{ Carboxyl groups } & $3685-3600$ & Free $\mathrm{OH}$ groups \\
\hline & & $3600-3500$ & $\mathrm{OH} \ldots \mathrm{OH}, \mathrm{OH} \ldots \mathrm{O}$ \\
\hline & & $3550-3200$ & $\begin{array}{l}\mathrm{OH}-\text { stretching vibration in phenols, alcohols, carboxyl } \\
\text { acids and water }\end{array}$ \\
\hline & & $3350-3310$ & Stretching vibration of $\mathrm{NH}_{2}, \mathrm{NH}$ \\
\hline & & $3150-3170$ & $\mathrm{OH} \ldots \mathrm{N}$ \\
\hline & & $3050-3030$ & Aromatic $\mathrm{CH}$ stretching vibration \\
\hline \multirow[t]{6}{*}{$3000-2700$} & \multirow[t]{6}{*}{ Aliphatic groups } & $2964 \sim$ & $-\mathrm{CH}_{2}-$ antisymmetric vibration \\
\hline & & $2960-2955$ & $\mathrm{CH}_{3}-$ antisymmetric stretching vibration \\
\hline & & 2943-2920 & $-\mathrm{CH}_{2}-$ symmetrical stretching vibration \\
\hline & & $2906-2891$ & $-\mathrm{CH}-$ vibration \\
\hline & & $2870-2867$ & $\mathrm{CH}_{3}-$ symmetrical stretching vibration \\
\hline & & $\sim 2852$ & $-\mathrm{CH}_{2}-$ antisymmetric stretching vibration \\
\hline \multirow[t]{16}{*}{$1800-1000$} & \multirow[t]{16}{*}{$\begin{array}{l}\text { Oxygen-containing functional groups } \\
\text { and aromatic groups in high-band }\end{array}$} & $1700 \sim$ & The vibration of $-\mathrm{COOH}$ \\
\hline & & $1697-1692$ & $\mathrm{C}=\mathrm{O}$ stretching vibration in an unsaturated carboxylic acid \\
\hline & & $1656-1641$ & Conjugated $\mathrm{C}=\mathrm{O}$ stretching vibration \\
\hline & & $1626-1503$ & Aromatic $\mathrm{C}=\mathrm{C}$ vibration \\
\hline & & $1455-1440$ & $\mathrm{CH}_{3}-, \mathrm{CH}_{2}-$ flexural vibration \\
\hline & & 1438 & Aromatic $\mathrm{C}=\mathrm{C}$ vibration \\
\hline & & $1393-1373$ & $\mathrm{CH}_{3}-$ vibration \\
\hline & & 1366 & $\mathrm{CH}_{3}-, \mathrm{CH}_{2}-$ flexure vibration \\
\hline & & $1295-1285$ & $\mathrm{C}-\mathrm{O}$ vibration in aryl ether \\
\hline & & 1260 & Oxygen atom in ether linkage \\
\hline & & $1223-1222$ & $\mathrm{C}-\mathrm{O}, \mathrm{OH}$ vibration in phenoxyl, ether \\
\hline & & $1174-1150$ & $\mathrm{C}-\mathrm{O}$ stretching vibration in phenol, ether \\
\hline & & 1134 & $\mathrm{C}-\mathrm{O}$ vibration in tertiary alcohol, ether \\
\hline & & $1100-1073$ & $\mathrm{C}-\mathrm{O}$ vibration in secondary alcohol, ether \\
\hline & & $1059-1000$ & $\mathrm{C}-\mathrm{O}-\mathrm{C}$ stretching vibration in $-\mathrm{O}-\mathrm{C},-\mathrm{O}-$ \\
\hline & & 974 & $\mathrm{C}-\mathrm{H}$ flexure vibration in formyl group \\
\hline \multirow[t]{4}{*}{$900-700$} & \multirow[t]{4}{*}{ Aromatic groups in low-band } & $816-829$ & Para-substituted benzene ring \\
\hline & & $800-786$ & Double meta-substitution benzene ring \\
\hline & & $778-752$ & Triple adj-substituted aromatic group \\
\hline & & 746 & Mono-substituted aromatic group \\
\hline
\end{tabular}

Table 4 Bands assignment of Raman Spectra $\left(1800-1000 \mathrm{~cm}^{-1}\right)$

\begin{tabular}{lll}
\hline Band name & Band position $/ \mathrm{cm}^{-1}$ & Vibration form and structure \\
\hline $\mathrm{D}_{1}$ & $1340-1358$ & Carbon edge atoms; impurity atoms and $s p^{2}$ carbon atoms (plane vibration) \\
$\mathrm{D}_{2}$ & $1600-1620$ & The surface of graphite layer $\left(\mathrm{E}_{2 \mathrm{~g}}\right.$ vibration) \\
$\mathrm{D}_{3}$ & $1500-1550$ & Vibration of amorphous $s p^{2}$ hybridization carbon atoms \\
$\mathrm{D}_{4}$ & $1180-1200$ & Lattice $s p^{2}-s p^{3}$ hybrid carbon atom; $\mathrm{C}-\mathrm{C}$ and $\mathrm{C}=\mathrm{C}$ in olefin (stretching vibration) \\
$\mathrm{G}$ & $1590-1610$ & Aromatic ring quadrant breathing; alkene $\mathrm{C}=\mathrm{C}$ \\
$\mathrm{S}_{1}$ & $\sim 1269$ & Aryl-alkyl ether; para-aromatics \\
$\mathrm{S}_{2}$ & $\sim 1060$ & C-H on aromatic rings; benzene (ortho-disubstituted) ring \\
\hline
\end{tabular}


where $m_{0}$ identifies the initial mass of sample; $t$ is an abbreviation for reaction time; $m_{\mathrm{t}}$ stands for the coal sample mass at time $t ; m_{\text {ash }}$ denotes the mass of residue after complete combustion.

Besides, the comprehensive combustion index $S$ was used to evaluate the combustibility of coal [35]. The calculation formula was as follows:

$S=\frac{(\mathrm{d} x / \mathrm{d} t)_{\text {mean }} \cdot(\mathrm{d} x / \mathrm{d} t)_{\max }}{T_{\mathrm{i}}^{2} \cdot T_{\mathrm{f}}}$

wherein $(\mathrm{d} x / \mathrm{d} t)_{\text {mean }}$ is the mean value of combustive rate; $(\mathrm{d} x / \mathrm{d} t)_{\max }$ stands for the maximum value of combustive rate; $T_{\mathrm{i}}$ represents the initial combustive temperature, at which the mass loss reaches 5\%; $T_{\mathrm{f}}$ represents the burnout temperature, which is the temperature corresponding to the mass loss of $95 \%$.

\section{Results and discussion}

\section{Comparison of proximate, ultimate, $\mathrm{HHV}$ and mass yield analyses}

The content of fixed carbon (FC) and HHV of P-X was compared with $\mathrm{H}-\mathrm{Y}$, where $X$ and $Y$ stood for the upgrading temperature. From Table 2, it could be deduced that for both P-X and $\mathrm{H}-\mathrm{Y}$, the number of $\mathrm{FC}$ and element carbon showed an upward trend with the increasing temperature. The content of volatile matter demonstrated an opposite trend. There was not a great deal of difference between pyrochar and RC. In contrast with the pyrochar, the FC of hydrochar revealed a relatively considerable increase from $60.13 \%(\mathrm{H}-220)$ to $68.06 \%(\mathrm{H}-340)$. The $\mathrm{FC}$ at $\mathrm{H}-220$ reached the level of P-340, and H-340 was increased by almost $9 \%$ relative to RC. The change in element carbon was similar with the pattern of FC. The carbon content of hydrochar was significantly higher than that of pyrochar, indicating a better modification effect of HTC.

Aiming to further consider the effect of the two upgrading methods on coal rank, the atomic ratio of $(\mathrm{H}+\mathrm{O})$ to $\mathrm{C}$ was introduced, where a smaller value of $(\mathrm{H}+\mathrm{O}) / \mathrm{C}$ indicated a higher coal rank [30]. According to the data in Table 1 , the values of $(\mathrm{O}+\mathrm{H}) / \mathrm{C}$ monotonically decreased with increasing temperature for both pyrochar and hydrochar. HHV of chars was positively correlated with the increasing temperature, and the HHV of hydrochar was higher than that of pyrochar at the same temperature. Figure 1 showed the variation of sample mass yield. It could be seen that the yields of pyrochar and hydrochar both declined with temperature increase. The yield of pyrochar dropped from 0.993 at P-220 to 0.969

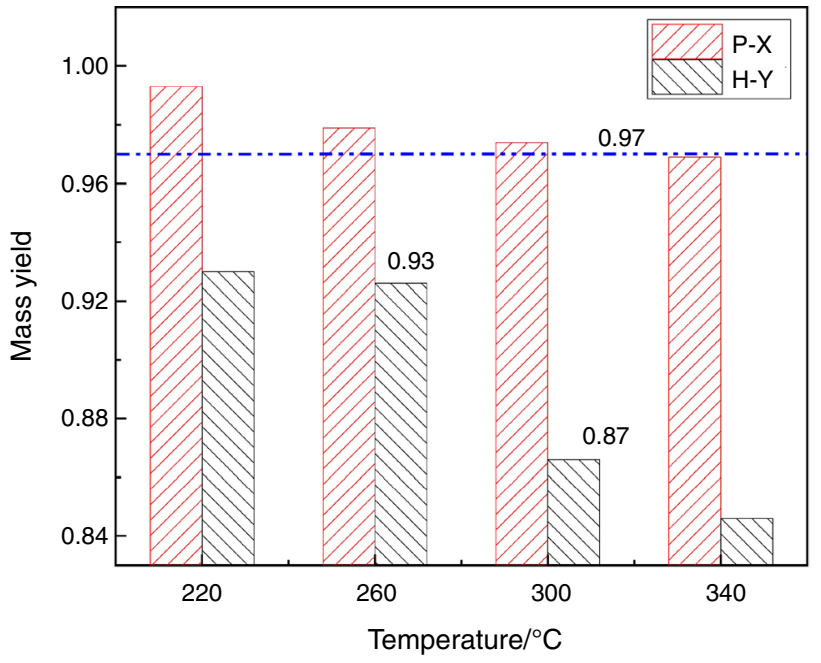

Fig. 1 Mass yields of pyrochar and hydrochar

at P-340 with no significant change. Different from the pyrolysis samples, a considerable decline occurred from 0.926 at $\mathrm{H}-260$ to 0.866 at $\mathrm{H}-300$.

For coal pyrolysis at around $300{ }^{\circ} \mathrm{C}$, it was mainly the period of drying and degassing [8]. This may be the reason why the $\mathrm{HHV},(\mathrm{H}+\mathrm{O}) / \mathrm{C}$ and mass yield of pyrochar were relatively close to that of RC. Unlike the pure pyrolysis process, the presence of water in HTC may accelerate the upgrading degree of low-rank coal [38]. Under the premise of $220-340{ }^{\circ} \mathrm{C}$, the above result also revealed that the upgrading effect of HTC was better than that of pyrolysis.

\section{Comparison of pore structure characteristics}

The surface morphology of char samples was characterized using SEM technology. According to Figs. 2 and 3, a comparison of pyrochar and hydrochar was performed. From images presented in Fig. 2, it could be seen that the surface of RC was overwhelmingly rough and irregular, without obvious pores. The surface of pyrochar was smoother and denser than RC. In other words, the microporous structure developed gradually with the increase in final temperature. According to Fig. 3, it could be found that within the scope of $220-300{ }^{\circ} \mathrm{C}$, the surface of hydrochar was smoother, showing more visible layered graphitic carbon. However, the microtopography of H-340 did not conform with the rule mentioned above. Due to the remarkable effect of HTC on devolatilization $\left(300-340{ }^{\circ} \mathrm{C}\right)$, the growth of pores was promoted. Under the high pressure of $340{ }^{\circ} \mathrm{C}$, the pore collapsed thereby causing the increase in surface roughness of H-340.

For further research, the pore structure was quantitatively analyzed using the method of nitrogen adsorption, and the result is shown in Table 5. The testing data demonstrated a monotonous growth with temperature in the 

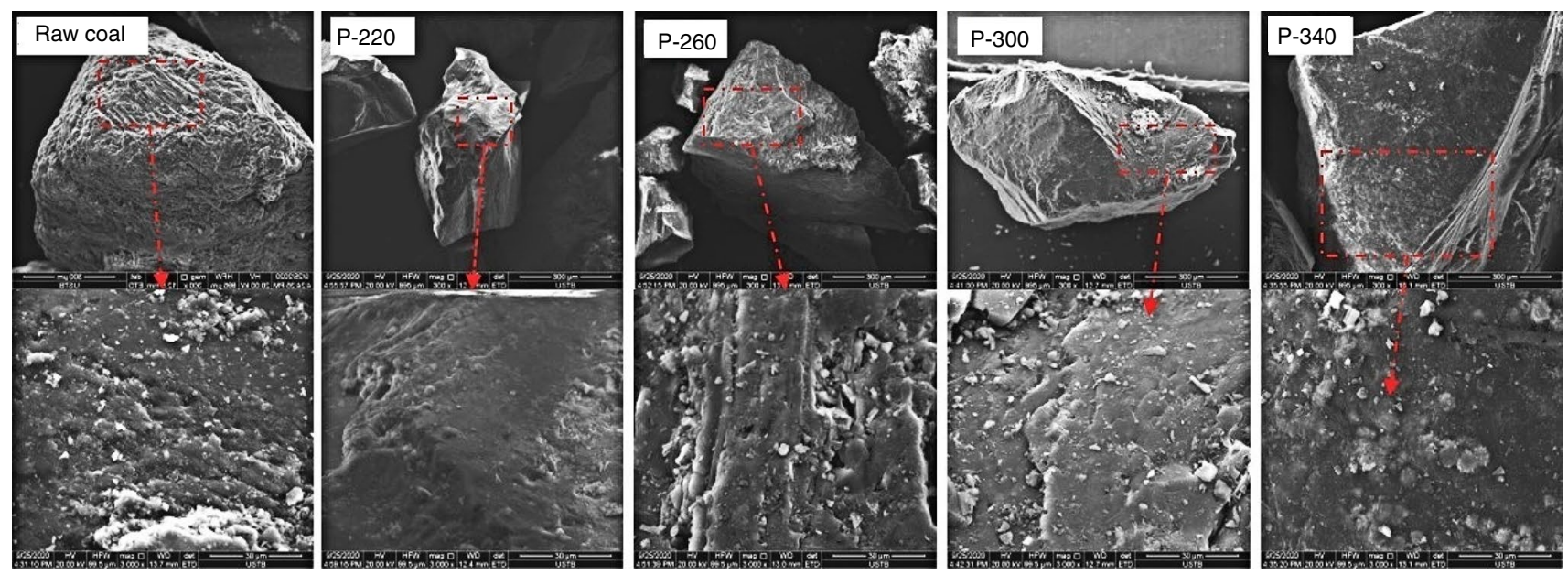

Fig. 2 SEM images of raw coal and pyrochar
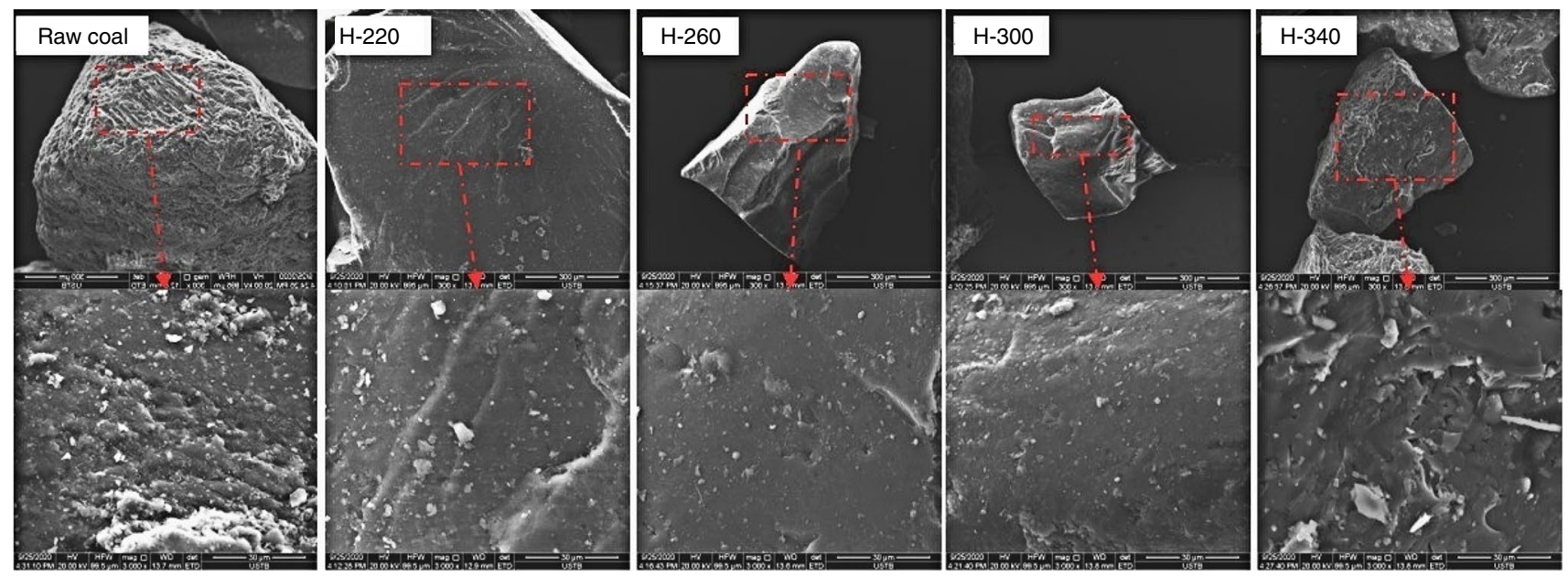

Fig. 3 SEM images of raw coal and hydrochar

Table 5 Pore structure parameter of samples

\begin{tabular}{llcr}
\hline Sample & $S_{\mathrm{t}} / \mathrm{m}^{2} \cdot \mathrm{g}^{-1}$ & $V_{\mathrm{t}} / 10^{-3} \cdot \mathrm{cm}^{3} \cdot \mathrm{g}^{-1}$ & $D_{\mathrm{a}} / \mathrm{nm}$ \\
\hline RC & 1.36 & 4.80 & 21.75 \\
P-220 & 1.40 & 5.37 & 20.43 \\
P-260 & 2.90 & 7.43 & 13.06 \\
P-300 & 3.07 & 9.32 & 10.97 \\
P-340 & 4.97 & 11.62 & 8.96 \\
H-220 & 3.14 & 8.24 & 15.66 \\
H-260 & 5.45 & 10.90 & 11.72 \\
H-300 & 7.75 & 12.55 & 8.22 \\
H-340 & 4.86 & 3.67 & 8.36 \\
\hline
\end{tabular}

number of specific surface area $\left(S_{\mathrm{t}}\right)$ and total pore volume $\left(V_{\mathrm{t}}\right)$. Meanwhile, the variation of average pore diameter $\left(D_{\mathrm{a}}\right)$ showed an opposite trend.
In fact, the pressure in HTC reactor almost increased exponentially with the increase in temperature. Especially under the surrounding of $340{ }^{\circ} \mathrm{C}$, the pressure could reach up to about $12 \mathrm{MPa}$. Due to the high temperature and pressure involved in HTC, the pores distributed on coal developed toward a direction of microporosity, indicating a smaller value of $D_{\mathrm{a}}$. Combined the proximate analysis (Table 2), we observed that the upgrading effect of HTC at $340{ }^{\circ} \mathrm{C}$ was the best. It meant that the reaction at this period was relatively violent and more tar would be generated, thereby making the pore structure deteriorate in turn. Consequently, the precipitous drop in $S_{\mathrm{t}}$ of H-340 could be attributed to the pore disruption and the blockage effect of tar. In general, the SEM image was consistent with the result of nitrogen adsorption. 


\section{Comparison of chemical structure characteristics}

\section{FTIR analysis}

The FTIR spectra $\left(500-4000 \mathrm{~cm}^{-1}\right)$ could effectively characterize the functional groups of coal sample. The initial data of FTIR are revealed in Fig. 4. It could be observed that the shapes of curves were similar to each other, only differing in peak height. The main absorption characteristic peaks identified four types of functional groups: $3000-3600 \mathrm{~cm}^{-1}$ for hydrogen bonding, $2800-3000 \mathrm{~cm}^{-1}$ for aliphatic chain, $1000-1800 \mathrm{~cm}^{-1}$ for oxygen-containing functional groups and $700-900 \mathrm{~cm}^{-1}$ for aromatic structure. In combination with Table 4, the wavenumber of the eleven peaks is determined in Fig. 4. It could be found that the wavenumber with the largest difference in peak height occurred at $1598 \mathrm{~cm}^{-1}$, which could be due to the aromatic $\mathrm{C}=\mathrm{C}$ vibration.

It was not advisable to directly use the original FTIR to analyze the content of functional groups. On the one hand, the difference in peak height may be induced by an inconsistent sample concentration. On the other hand, there were large numbers of overlapping peaks in initial FTIR curves. The characteristic parameters of functional groups could be calculated according to the integrated area of fitted peak. Based on the Beer-Lambert law [39], the following equations were applied to perform the calculation of FTIR parameter.

$I_{1}=\mathrm{CH}_{3} / \mathrm{CH}_{2}$

$I_{2}=\mathrm{C}_{\mathrm{ar}} / \mathrm{H}_{\mathrm{al}}$
$I_{3}=\mathrm{C}_{\mathrm{ar}} /\left(\mathrm{COOH}+\mathrm{C}_{\mathrm{ar}}\right)$

$I_{4}=(\mathrm{C}=\mathrm{O}) / \mathrm{C}_{\mathrm{ar}}$

$I_{5}=\mathrm{COOH} / \mathrm{C}_{\mathrm{ar}}$

$I_{6}=\left(\mathrm{R}^{\prime}-\mathrm{O}-\mathrm{R}\right) / \mathrm{C}_{\mathrm{ar}}$

wherein ar, al and $\mathrm{R}$ (or $\mathrm{R}^{\prime}$ ) were the abbreviation for the aromatic group, aliphatic group and hydrocarbyl, respectively; $I_{1}$ to $I_{6}$ represented the length of aliphatic side chain, structure evolution of aromatic group, organic matter maturity, carbonyl content, carboxyl content and ether content, respectively; $\mathrm{CH}_{3}, \mathrm{CH}_{2}, \mathrm{C}_{\mathrm{ar}}, \mathrm{H}_{\mathrm{ar}}, \mathrm{COOH}, \mathrm{C}=\mathrm{O}$, and $\mathrm{R}^{\prime}-\mathrm{O}-\mathrm{R}$ stood for the functional groups, corresponding to the integral area of fitted peak.

The focus of the calculation was oxygen-containing functional groups and aromatic hydrocarbons. Firstly, according to the band assignment in Table 3 , the fitted curves of oxygen-containing functional groups (Fig. 5) and hydrocarbons (Fig. 6) were obtained using Gaussian fitting. Secondly, taking advantage of Eqs. (5)-(10), the parameters were calculated (Table 6). It could be found from Table 6 that with the increase in temperature, there was a downward trend in the values of $I_{1}, I_{4}$ and $I_{5}$. Meanwhile, the changes of $I_{2}$ and $I_{3}$ both showed an upward trend. The decline in $I_{1}$ was due to the decomposition of long aliphatic side chains. Then, with the condensation reaction of broken unsaturated bonds completed, aromatic hydrocarbon was generated, leading to an increase in $I_{2}$. Many recent evidences suggested the importance of oxygen-containing functional groups in coal evolution [40-43]. The maturity of organic matter $\left(I_{3}\right)$ was

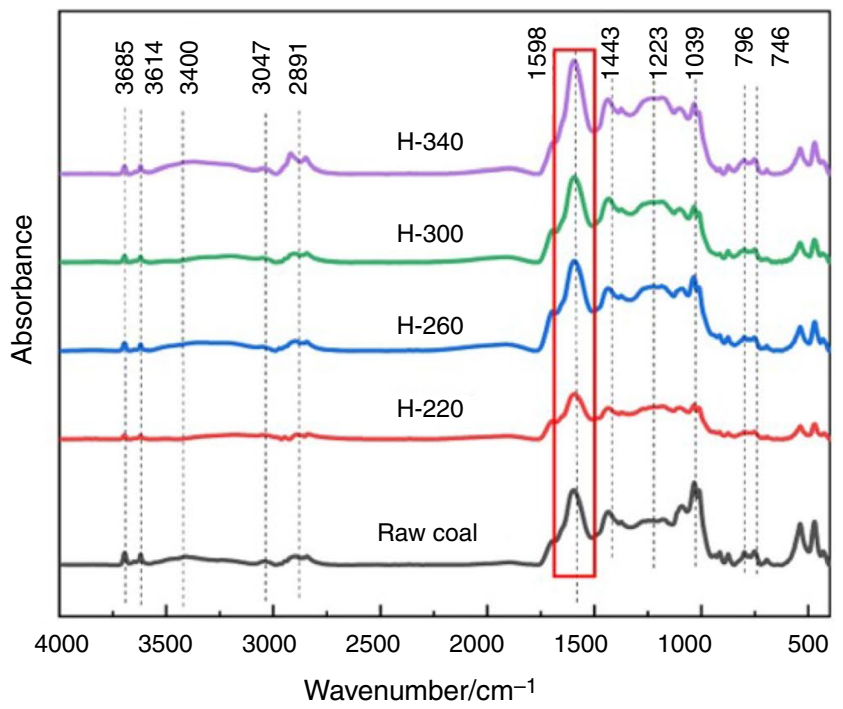

Fig. 4 FTIR spectra of raw coal and eight chars 
Fig. 5 Peak-fitting results of $1800-1000 \mathrm{~cm}^{-1}$ band

Fig. 6 Peak-fitting results of $3000-2700 \mathrm{~cm}^{-1}$ band

Table 6 The characteristic parameter of FTIR spectra
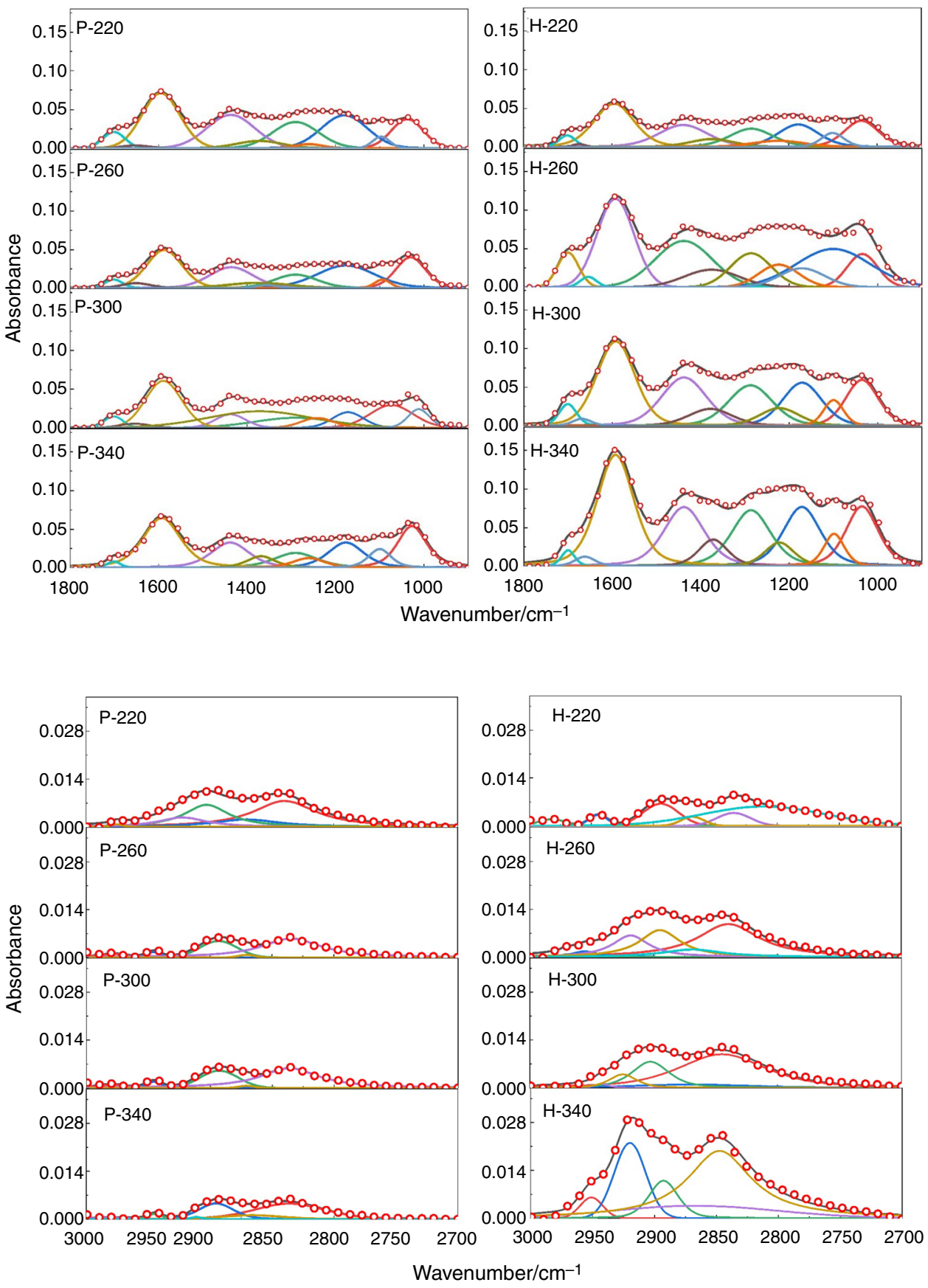

\begin{tabular}{llrllll}
\hline Sample & $\mathrm{CH}_{3} / \mathrm{CH}_{2}$ & $\mathrm{C}_{\mathrm{ar}} / \mathrm{H}_{\mathrm{al}}$ & $\mathrm{C}_{\mathrm{ar}} /\left(\mathrm{COOH}+\mathrm{C}_{\mathrm{ar}}\right)$ & $(\mathrm{C}=\mathrm{O}) / \mathrm{C}_{\mathrm{ar}}$ & $\mathrm{COOH} / \mathrm{C}_{\mathrm{ar}}$ & $\left(\mathrm{R}^{\prime}-\mathrm{O}-\mathrm{R}\right) / \mathrm{C}_{\mathrm{ar}}$ \\
\hline $\mathrm{RC}$ & 0.33 & 5.82 & 0.90 & 0.16 & 0.11 & 0.84 \\
$\mathrm{P}-220$ & 0.26 & 5.95 & 0.89 & 0.17 & 0.13 & 0.84 \\
$\mathrm{P}-260$ & 0.22 & 7.20 & 0.90 & 0.14 & 0.13 & 0.71 \\
$\mathrm{P}-300$ & 0.14 & 8.00 & 0.89 & 0.07 & 0.12 & 0.71 \\
$\mathrm{P}-340$ & 0.13 & 11.21 & 0.90 & 0.04 & 0.10 & 0.65 \\
$\mathrm{H}-220$ & 0.28 & 9.07 & 0.89 & 0.05 & 0.11 & 0.52 \\
$\mathrm{H}-260$ & 0.22 & 9.83 & 0.82 & 0.05 & 0.23 & 0.41 \\
$\mathrm{H}-300$ & 0.10 & 10.28 & 0.89 & 0.04 & 0.12 & 0.39 \\
$\mathrm{H}-340$ & 0.07 & 13.03 & 0.95 & 0.02 & 0.05 & 0.35 \\
\hline
\end{tabular}


closely related to the concentration of oxygen-containing functional groups $\left(I_{5}\right)$.

The two upgrading methods, pyrolysis and HTC, affected $I_{1}-I_{6}$ to different degrees. The efficiency of HTC to remove aliphatic side chains was steeply higher than that of pyrolysis between 300 and $340{ }^{\circ} \mathrm{C}$. What is more, it could be found from the values of $I_{4}$ to $I_{6}$ that, probably due to the presence of high-temperature moisture, HTC was superior in removing oxygen-containing functional groups. In combination with the atomic ratios (Table 2), the variation on carboxyl group content $\left(I_{5}\right)$ was more correlated with that of atomic ratios. So, the carboxyl group had a large influence on chemical structure of a coal, which perfectly coincided with what Xie [8] emphasized. The pattern of variation in presented data (Table 6) was consistent with those highlighted by previous authors [27-29]. It was worth noting that there were some discrepancies regarding carboxyl among HTC samples. Compared with $I_{5}$ of RC, the hydrochar appeared small increasing, then, sharp decline, with the maximum value appearing at $0.23(\mathrm{H}-260)$. Zeng et al. [44] suggested that the high-temperature water vapor $\left(250-300^{\circ} \mathrm{C}\right)$ would promote the hydrolysis course of weak covalent compounds (ether, ester, and acid anhydride), resulting in the regeneration of carboxyl group. The water in HTC was in a subcritical state; therefore, it also boosted the hydrolysis of ether and ester bonds to form new carboxyl groups. This was the cause for the sharp increase in $\mathrm{COOH}$ content of $\mathrm{H}-260$, corresponding to the precipitous decline in $I_{6}$ value. After $260{ }^{\circ} \mathrm{C}$, the decarboxylation efficiency of HTC was enhanced, thereby resulting in decline in the amount of $\mathrm{COOH}$.

Zhao et al. [45] suggested that under HTC environment, $\mathrm{COOH}$ would only be thermally decomposed, but not hydrolyzed. According to the experimental result from Table 6, HTC did make a positive impact on decarboxylation. On the one hand, as shown in Fig. 7a, b, the presence of water molecules facilitated the hydrolysis of ether bond and ester group. The water could act as a solvent to extract reaction products composed of small molecules, thus reducing the stability of molecular structure and accelerating the reaction efficiency. On the other hand, the water molecules in the subcritical state were a high activity catalyst. As shown in Fig. $7 \mathrm{c}, \mathrm{d}$, the carbon atom attached to $\mathrm{COOH}$ on the benzene ring was broken down by $\mathrm{H}^{+}$, which in turn caused the chemical bonds to break. Therefore, these two aspects may lead to the superiority in HTC over pyrolysis in terms of decarboxylation.

\section{Raman analysis}

The transformation of the carbon structure was quantified using Raman spectra. In combination with Table 4, the peakdifferentiating and imitating result is presented in Fig. 8. It could be found that the result had the advantage of high goodness of fit and satisfactory effect. Based on the fitted peak, Table 7 showed the carbon structure parameters: $A_{\mathrm{D} 3+\mathrm{D} 4} / A_{\mathrm{G}}, A_{\mathrm{G}} / A_{\mathrm{All}}$, and $A_{\mathrm{D} 3} / A_{\mathrm{All}}$, wherein $A$ indicated the integration area of corresponding peak [46]. More specifically, $A_{\mathrm{D} 3+\mathrm{D} 4} / A_{\mathrm{G}}, A_{\mathrm{G}} / A_{\mathrm{All}}$, and $A_{\mathrm{D} 3} / A_{\mathrm{All}}$ were the measurements of disorder degree of carbon material, order degree and the number of active sites, respectively. It could be found that the pyrolysis and HTC had discrepant effects on the three structural parameters. As for the pyrochars, there was a gradual decline reduction in $A_{\mathrm{D} 3} / A_{\mathrm{All}}$ and reached a minimum figure of 0.09. Meanwhile, $A_{\mathrm{G}} / A_{\mathrm{All}}$ revealed an opposite trend, with an increase in value from 0.17 (P-220) to 0.22 (P-340). Besides, there were lots of differences between pyrochar and hydrochar in terms of $A_{\mathrm{D} 3+\mathrm{D} 4} / A_{\mathrm{G}}$. A considerable decrease occurred in $A_{\mathrm{D} 3+\mathrm{D} 4} / A_{\mathrm{G}}$ of hydrochar
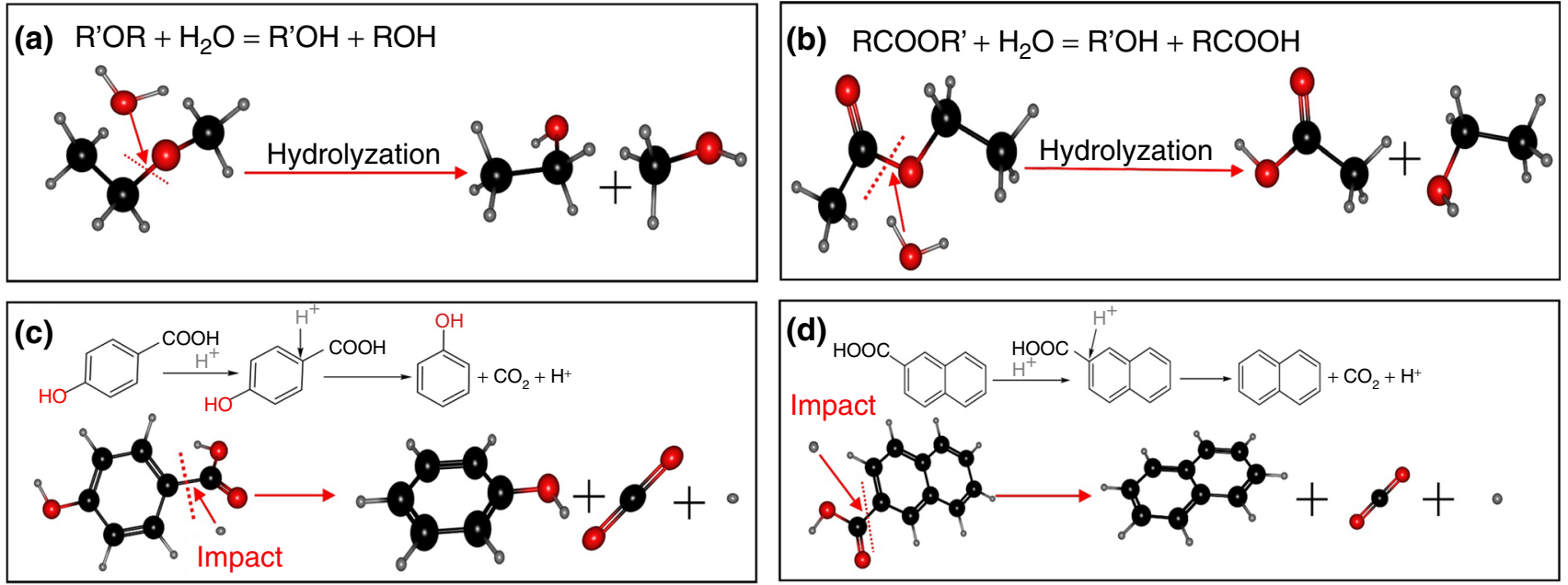

Fig. 7 The quintessential reaction of some functional groups in HTC 


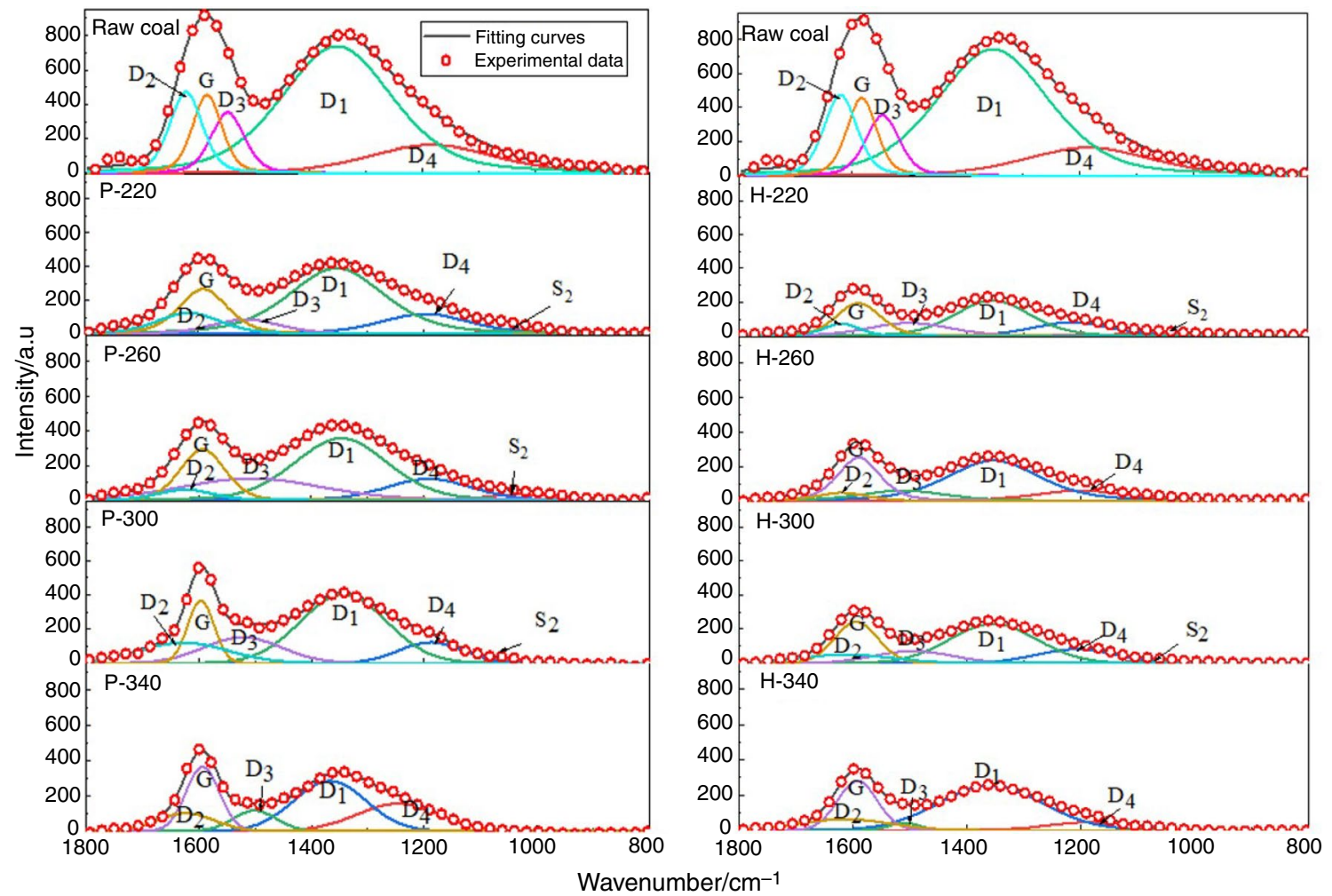

Fig. 8 Raman spectra of samples

Table 7 Carbon structure parameters of sample

\begin{tabular}{lcrrrrllll}
\hline Sample & \multicolumn{1}{c}{$A_{\mathrm{D} 1}$} & \multicolumn{1}{c}{$A_{\mathrm{D} 2}$} & \multicolumn{1}{c}{$A_{\mathrm{D} 3}$} & \multicolumn{1}{c}{$A_{\mathrm{D} 4}$} & \multicolumn{1}{c}{$A_{\mathrm{G}}$} & \multicolumn{1}{c}{$A_{\mathrm{D} 3+\mathrm{D} 4} / A_{\mathrm{G}}$} & $A_{\mathrm{G}} / A_{\mathrm{All}}$ & $A_{\mathrm{D} 3} / A_{\mathrm{All}}$ & $A_{\mathrm{S} 2}$ \\
\hline RC & 56.62 & 11.07 & 8.48 & 14.22 & 9.61 & 2.36 & 0.10 & 0.08 & - \\
P-220 & 48.58 & 10.47 & 7.97 & 14.13 & 17.17 & 1.29 & 0.17 & 0.08 & 1.69 \\
P-260 & 41.90 & 14.17 & 11.48 & 13.06 & 16.57 & 1.48 & 0.17 & 0.11 & 2.81 \\
$\mathrm{P}-300$ & 39.95 & 14.02 & 15.63 & 10.42 & 18.82 & 1.38 & 0.19 & 0.16 & 1.16 \\
$\mathrm{P}-340$ & 36.39 & 10.29 & 8.98 & 22.79 & 21.55 & 1.47 & 0.22 & 0.09 & - \\
$\mathrm{H}-220$ & 38.36 & 6.36 & 15.35 & 15.46 & 20.75 & 1.48 & 0.21 & 0.15 & 3.73 \\
$\mathrm{H}-260$ & 47.51 & 5.29 & 11.23 & 12.10 & 21.87 & 1.07 & 0.22 & 0.11 & - \\
$\mathrm{H}-300$ & 41.78 & 7.46 & 11.39 & 13.38 & 23.83 & 1.04 & 0.24 & 0.12 & 1.16 \\
$\mathrm{H}-340$ & 53.71 & 11.70 & 2.62 & 7.82 & 24.15 & 0.43 & 0.27 & 0.03 & - \\
\hline
\end{tabular}

from 1.48 (H-220) to $0.43(\mathrm{H}-340)$, contrasting the fluctuation change in pyrochar.

The pyrolysis and HTC had diverse effects on the three structural parameters. During the pyrolysis process at $220-260{ }^{\circ} \mathrm{C}$, mostly the crystal water and adsorbed gases $\left(\mathrm{CO}_{2}, \mathrm{CO}, \mathrm{N}_{2}\right.$ and $\left.\mathrm{CH}_{4}\right)$ were removed from the coal [8]. Consequently, the number of condensed aromatics $\left(A_{\mathrm{G}} / A_{\mathrm{All}}\right)$ and active sites $\left(A_{\mathrm{D} 3} / A_{\mathrm{All}}\right)$ in pyrochar did not change dramatically with this temperature range. In addition, for pyrolysis of low-rank coal, the noticeable chemical reactions occurred after $300{ }^{\circ} \mathrm{C}$. So, the ordered degree of sample $\left(A_{\mathrm{G}} / A_{\mathrm{All}}\right)$ increased from 0.19 (P-300) to 0.22 (P-340). Meanwhile, with the decomposition of some unstable functional groups, lattice defects on carbon matrix were further formed, resulting in the highest number of active sites $\left(A_{\mathrm{D} 3} / A_{\mathrm{All}}\right)$ of P-300. At $340{ }^{\circ} \mathrm{C}$, the amorphous carbon in pyrochar continued to convert to graphitic carbon, thereby corresponding to a lower number of active sites. Compared with the pyrolysis process, it could be found that the regularity of $A_{\mathrm{G}} / A_{\mathrm{All}}$ and $A_{\mathrm{D} 3} / A_{\mathrm{All}}$ to temperature was more pronounced for hydrochar. Accordingly, HTC could fulfill the condensation reaction of carbon and cleavage reaction of heterocycle at a lower temperature. 


\section{Comparison of combustion behavior}

The mechanism and kinetics of the thermal combustion of pyrochar and hydrochar were studied by means of the thermogravimetric analysis method (TGA). The experimental conversion $x$ (TG curve) and conversion rate $\mathrm{d} x / \mathrm{d} t$ (DTG curve) at different heating rates are shown in Figs. 9 and 10, respectively. The characteristic parameters of samples are listed in Table 8 by using Eq. (4).

The combustion of pulverized coal could be divided into two main stages: the first stage being the volatiles and the second stage being the residual carbon. For all pyrolysis samples but P-220, there were two peaks in DTG, corresponding to the combustion of volatiles and residual carbon, respectively. For the hydrochars, there was only one broad peak on DTG, indicating a more concentrated combustion period. That was, a synergism was found between the combustion of volatiles and residual carbon, mainly due to the high value of specific surface area. The comprehensive combustion characteristic index $(S)$ was adapted to quantitative research on combustibility. It could be seen from Table 8 that $S$ value increased exponentially while the heating rate increased. At a higher heating rate $\left(20{ }^{\circ} \mathrm{C} \cdot \mathrm{min}^{-1}\right)$, the combustibility of hydrochar was acutely better than that of pyrochar.

In order to quantitatively describe the combustion process of the coal samples, kinetic calculations and analyses were performed. Based on the summary of Peterson's previous results, the random pore model (RPM) was developed by Bhatia and Permutter [47, 48]. There were three decisive assumptions in RPM. Firstly, the pores randomly distributed in solid particles were cylindrical with discrepant sizes. Secondly, these pores were independent and not connected with each other. Finally, all reactions took place at the pore surface and no solid products were formed. The relationship between the pore surface area $S$, conversion rate $x$ and time in RPM was shown below.

$$
\begin{aligned}
& \frac{S}{S_{0}}=\frac{1-x}{1-\tau / \sigma} \sqrt{1-\psi \ln \left[\frac{1-x}{(1-\tau / \sigma)^{3}}\right]} \\
& x=1-(1-\tau / \sigma)^{3} \cdot \exp (-\tau(1+\psi \tau / 4))
\end{aligned}
$$

where $\tau$ is an abbreviation for dimensionless time; $S_{0}$ indicates the initial specific surface area, $\mathrm{m}^{2} \cdot \mathrm{m}^{-3} ; \sigma$ and
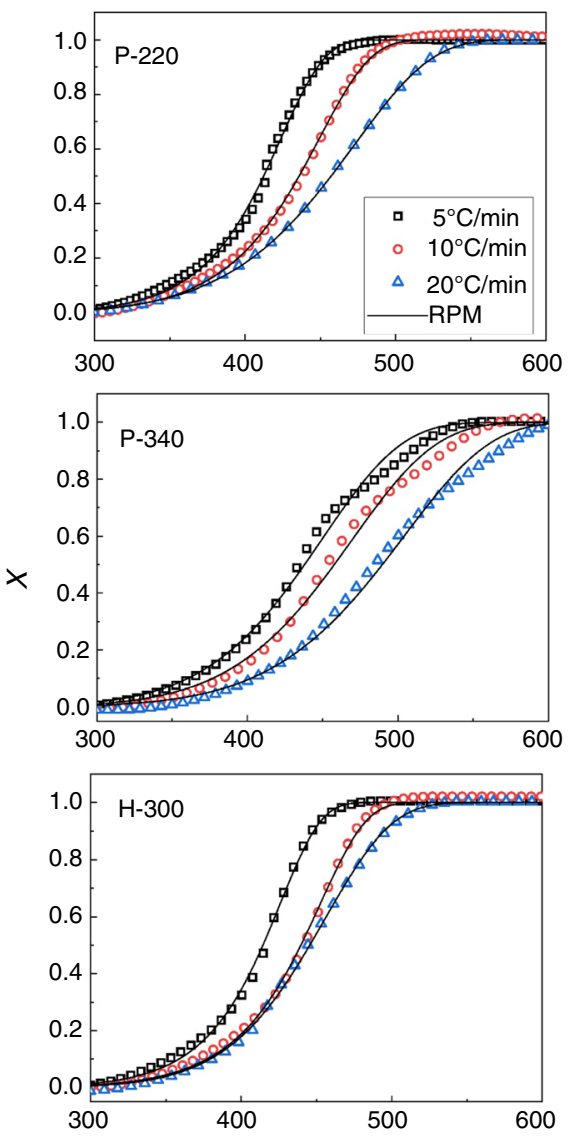
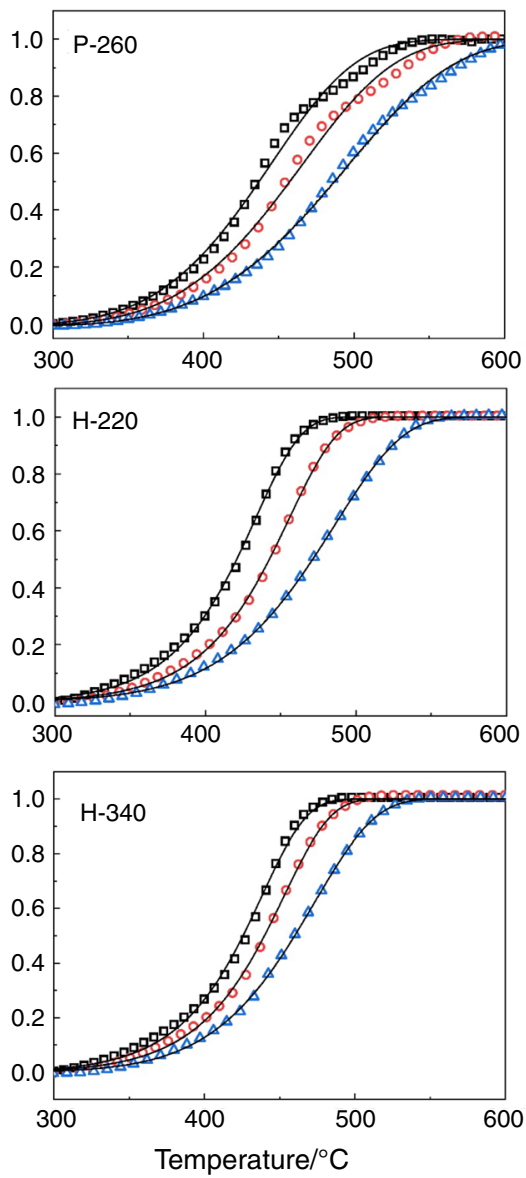
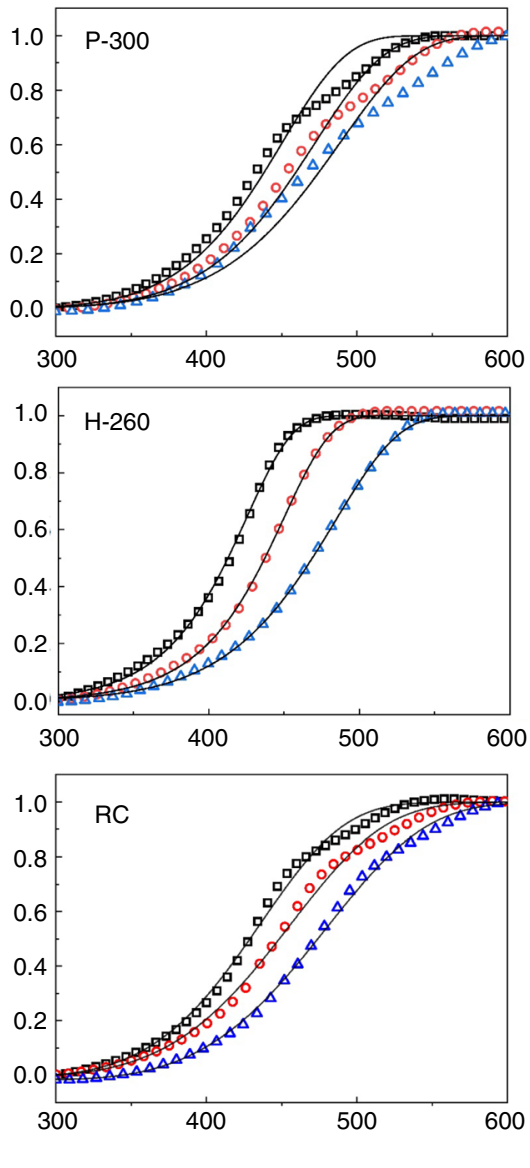

Fig. 9 Experimental conversion curves and calculated results with RPM model 

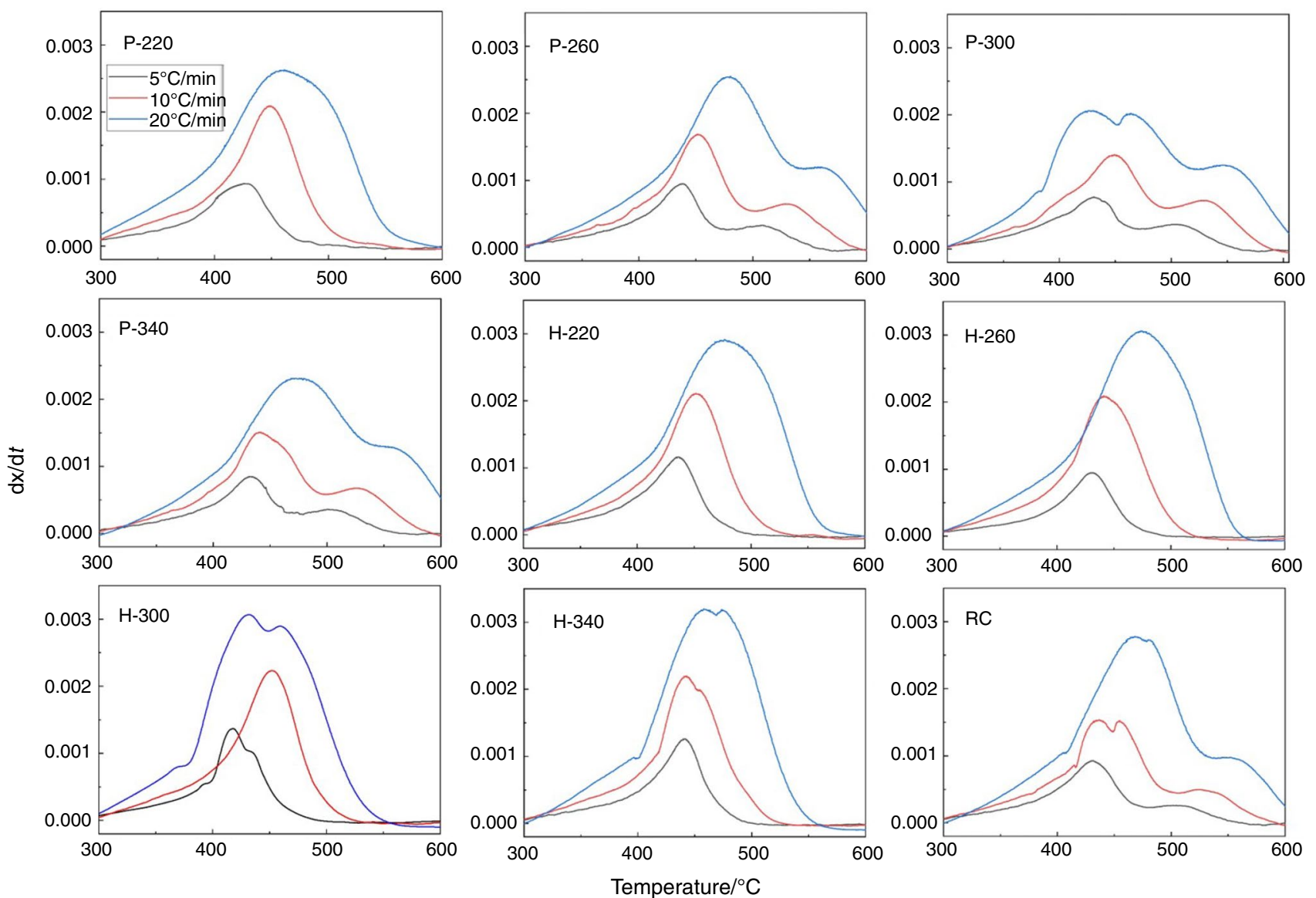

Fig. 10 Experimental conversion rate under various heating rate

$\psi$ represent the size and structural parameter of particle, respectively.

The specific expressions of $\tau, \psi$ and $\sigma$ were as follows:

$\tau=k C^{n} S_{0} t /\left(1-\varepsilon_{0}\right)$

$\psi=4 \pi L_{0}\left(1-\varepsilon_{0}\right) / S_{0}^{2}$

$\sigma=r_{0} S_{0} /\left(1-\varepsilon_{0}\right)$

where $L_{0}$ is the initial length of pore, $\mathrm{m}^{2} \cdot \mathrm{m}^{-3} ; r_{0}$ denotes the initial radius of sample particle, $\mathrm{m}$; $C$ stands for the concentration of reactant gas, $\mathrm{mol} \cdot \mathrm{m}^{-3} ; n$ is the reaction order; $k$ identifies the apparent rate constant of reaction, $\min ^{-1} ; t$ is the reaction time, s.

$x=1-\exp \left\{-\left[A_{0} \frac{\left(T-T_{0}\right)}{\beta} \exp \left(\frac{-E}{R T}\right)\right]\left[1+A_{1} \frac{\left(T-T_{0}\right)}{4 \beta} \exp \left(\frac{-E}{R T}\right)\right]\right\}$ 
Table 8 Representative combustion parameters of samples

\begin{tabular}{|c|c|c|c|c|c|c|}
\hline Sample & $\begin{array}{l}\text { Heating } \\
\text { rate } /{ }^{\circ} \mathrm{C} \cdot \min ^{-1}\end{array}$ & $T_{\mathrm{i}} /{ }^{\circ} \mathrm{C}$ & $T_{\mathrm{f}} /{ }^{\circ} \mathrm{C}$ & $(\mathrm{d} x / \mathrm{d} t)_{\max } / \mathrm{s}^{-1}$ & $(\mathrm{~d} x / \mathrm{d} t)_{\text {mean }} / \mathrm{s}^{-1}$ & $S$ \\
\hline & 5 & 337.5 & 516.2 & $8.80 \mathrm{E}-4$ & $2.64 \mathrm{E}-4$ & $7.90 \mathrm{E}-16$ \\
\hline \multirow[t]{3}{*}{$\mathrm{RC}$} & 10 & 347.5 & 526.5 & $1.59 \mathrm{E}-3$ & $3.94 \mathrm{E}-4$ & $2.04 \mathrm{E}-15$ \\
\hline & 20 & 377.4 & 569.8 & $2.76 \mathrm{E}-3$ & $9.59 \mathrm{E}-4$ & $7.42 \mathrm{E}-15$ \\
\hline & 5 & 293.7 & 460.1 & $9.10 \mathrm{E}-4$ & $2.62 \mathrm{E}-4$ & $1.01 \mathrm{E}-15$ \\
\hline \multirow[t]{3}{*}{ P-220 } & 10 & 340.1 & 475.9 & $2.18 \mathrm{E}-3$ & $5.63 \mathrm{E}-4$ & $4.36 \mathrm{E}-15$ \\
\hline & 20 & 345.0 & 528.4 & $2.62 \mathrm{E}-3$ & $9.83 \mathrm{E}-4$ & $8.41 \mathrm{E}-15$ \\
\hline & 5 & 344.8 & 521.4 & $9.40 \mathrm{E}-4$ & $3.21 \mathrm{E}-4$ & $1.00 \mathrm{E}-15$ \\
\hline \multirow[t]{3}{*}{ P-260 } & 10 & 358.5 & 533.3 & $1.49 \mathrm{E}-3$ & $4.11 \mathrm{E}-4$ & $1.90 \mathrm{E}-15$ \\
\hline & 20 & 376.2 & 584.2 & $2.52 \mathrm{E}-3$ & $9.08 \mathrm{E}-4$ & $6.33 \mathrm{E}-15$ \\
\hline & 5 & 342.0 & 524.0 & $7.70 \mathrm{E}-4$ & $3.16 \mathrm{E}-4$ & $8.10 \mathrm{E}-16$ \\
\hline \multirow[t]{3}{*}{ P-300 } & 10 & 356.0 & 534.6 & $1.13 \mathrm{E}-3$ & $3.51 \mathrm{E}-4$ & $1.24 \mathrm{E}-15$ \\
\hline & 20 & 368.7 & 575.5 & $2.04 \mathrm{E}-3$ & $9.52 \mathrm{E}-4$ & $5.56 \mathrm{E}-15$ \\
\hline & 5 & 339.2 & 522.7 & $8.40 \mathrm{E}-4$ & $2.28 \mathrm{E}-4$ & $6.40 \mathrm{E}-16$ \\
\hline \multirow[t]{3}{*}{ P-340 } & 10 & 360.2 & 531.6 & $1.37 \mathrm{E}-3$ & $3.07 \mathrm{E}-4$ & $1.30 \mathrm{E}-15$ \\
\hline & 20 & 381.5 & 582.5 & $2.31 \mathrm{E}-3$ & $9.21 \mathrm{E}-4$ & $5.81 \mathrm{E}-15$ \\
\hline & 5 & 334.2 & 464.9 & $1.14 \mathrm{E}-3$ & $2.80 \mathrm{E}-4$ & $1.17 \mathrm{E}-15$ \\
\hline \multirow[t]{3}{*}{ H-220 } & 10 & 352.0 & 481.1 & $2.28 \mathrm{E}-3$ & $5.27 \mathrm{E}-4$ & $4.08 \mathrm{E}-15$ \\
\hline & 20 & 366.9 & 534.4 & $2.91 \mathrm{E}-3$ & $10.00 \mathrm{E}-4$ & $8.80 \mathrm{E}-15$ \\
\hline & 5 & 330.7 & 459.1 & $9.20 \mathrm{E}-4$ & $3.36 \mathrm{E}-4$ & $1.16 \mathrm{E}-15$ \\
\hline \multirow[t]{3}{*}{ H-260 } & 10 & 345.8 & 475.4 & $2.11 \mathrm{E}-3$ & $5.57 \mathrm{E}-4$ & $4.10 \mathrm{E}-15$ \\
\hline & 20 & 363.9 & 529.0 & $3.05 \mathrm{E}-3$ & $10.20 \mathrm{E}-4$ & $9.56 \mathrm{E}-15$ \\
\hline & 5 & 330.1 & 455.7 & $1.06 \mathrm{E}-3$ & $3.24 \mathrm{E}-4$ & $1.30 \mathrm{E}-15$ \\
\hline \multirow[t]{3}{*}{ H-300 } & 10 & 348.2 & 475.6 & $2.37 \mathrm{E}-3$ & $4.24 \mathrm{E}-4$ & $3.47 \mathrm{E}-15$ \\
\hline & 20 & 358.9 & 507.9 & $3.03 \mathrm{E}-3$ & $10.50 \mathrm{E}-4$ & $10.20 \mathrm{E}-15$ \\
\hline & 5 & 335.0 & 467.4 & $1.20 \mathrm{E}-3$ & $2.95 \mathrm{E}-4$ & $1.29 \mathrm{E}-15$ \\
\hline \multirow[t]{2}{*}{$\mathrm{H}-340$} & 10 & 348.8 & 477.8 & $2.00 \mathrm{E}-3$ & $3.46 \mathrm{E}-4$ & $2.38 \mathrm{E}-15$ \\
\hline & 20 & 365.0 & 517.6 & $3.15 E-3$ & $11.90 \mathrm{E}-4$ & $11.65 \mathrm{E}-15$ \\
\hline
\end{tabular}

Table 9 Kinetic parameters of samples for RPM model

\begin{tabular}{lllll}
\hline Sample & $k_{0} / \mathrm{min}^{-1}$ & $E / \mathrm{kJ} \cdot \mathrm{mol}^{-1}$ & $\psi$ & $R^{2}$ \\
\hline RC & 122,435 & 83.74 & $3.37 \mathrm{E}-19$ & 0.9784 \\
P-220 & 88,260 & 83.14 & 8.79 & 0.9908 \\
P-260 & 33,070 & 77.95 & $9.02 \mathrm{E}-19$ & 0.9792 \\
P-300 & 17,046 & 74.05 & $5.86 \mathrm{E}-16$ & 0.9666 \\
P-340 & 27,395 & 76.67 & $4.91 \mathrm{E}-18$ & 0.9968 \\
H-220 & 89,160 & 83.32 & 4.13 & 0.9897 \\
H-260 & 60,960 & 82.17 & 5.77 & 0.9924 \\
H-300 & 88,200 & 83.00 & 2.36 & 0.9918 \\
H-340 & 174,300 & 85.91 & 7.22 & 0.9863 \\
\hline
\end{tabular}

wherein $A_{0}=k_{0} C^{\mathrm{n}} S_{0} /\left(1-\varepsilon_{0}\right), \quad A_{1}=4 \pi L_{0} k_{0} C^{\mathrm{n}} / S_{0}$, $A_{1} / A_{0}=\psi$.

On the basis of Eq. (18), a nonlinear fitting was used to obtain $k_{0}$ and $E$, and the result is revealed in Table 9. Also, the fitted curves were shown by solid line of Fig. 9. The coefficient of determination was intensely high in all cases, meaning a high degree of fitting between RPM simulation and experimental data. The calculated activation energy of pyrochar was in the range of $74-83 \mathrm{~kJ} \cdot \mathrm{mol}^{-1}$. Meanwhile, the activation energy of hydrochar was ranged from 82 to $86 \mathrm{~kJ} \cdot \mathrm{mol}^{-1}$. The activation energies due to the oxidation of low-rank coal were reported to be in the range of 61-79 $\mathrm{kJ} \cdot \mathrm{mol}^{-1}$ [49]. Therefore, the $E$ calculated in this paper was deeply consistent with the result announced in the previous literature.

It was worth noting that there was a difference between the kinetic parameters of pyrochar and hydrochar. The activation energy of hydrochar $\left(83.32 \mathrm{~kJ} \cdot \mathrm{mol}^{-1}, 82.17 \mathrm{~kJ} \cdot \mathrm{mol}^{-1}\right.$, $83.00 \mathrm{~kJ} \cdot \mathrm{mol}^{-1}$ and $\left.85.91 \mathrm{~kJ} \cdot \mathrm{mol}^{-1}\right)$ was overall higher than that of pyrochar $\left(83.14 \mathrm{~kJ} \cdot \mathrm{mol}^{-1}, 77.95 \mathrm{~kJ} \cdot \mathrm{mol}^{-1}\right.$, $74.05 \mathrm{~kJ} \cdot \mathrm{mol}^{-1}$ and $\left.76.67 \mathrm{~kJ} \cdot \mathrm{mol}^{-1}\right)$.

Activation energy could be used to measure the likelihood of occurrence of a chemical reaction. The essential factor affecting the activation energy of a chemical reaction was the number of molecules that can collide effectively. A higher number of effective collisions corresponded to a smaller activation energy. On the one hand, the pyrolysis treatment in this work did not substantially 
change the content of oxygen-containing functional groups and aromatic hydrocarbons. It could be concluded that the chemical structures of pyrochar had less influence on the combustion activation energy. On the other hand, from the result of nitrogen adsorption, the specific surface area of pyrochar gradually increased from $1.40 \mathrm{~m}^{2} \cdot \mathrm{g}^{-1}$ at $220{ }^{\circ} \mathrm{C}$ to $4.97 \mathrm{~m}^{2} \cdot \mathrm{g}^{-1}$ at $340{ }^{\circ} \mathrm{C}$. The increase in specific surface area allowed the particles to adsorb more air per unit time, thereby increasing the effective collision probability between activated molecules. Thus, in contrast with the activation energy of RC $\left(83.74 \mathrm{~kJ} \cdot \mathrm{mol}^{-1}\right)$, the decline in activation energy of pyrochar could be attributed to the effect of specific surface area. The specific surface area of hydrochars increased from $3.14 \mathrm{~m}^{2} \cdot \mathrm{g}^{-1}$ at $\mathrm{H}-220$ to 4.86 $\mathrm{m}^{2} \cdot \mathrm{g}^{-1}$ at $\mathrm{H}-340$. However, the hydrochar had a lower content of oxygen-containing functional groups $(\mathrm{C}=\mathrm{O}$, $\left.\mathrm{COOH}, \mathrm{R}^{\prime}-\mathrm{O}-\mathrm{R}\right)$ and a higher ordering degree of the carbon structure $\left(A_{\mathrm{G}} / A_{\mathrm{All}}\right)$. Thus, the stability of chemical structure weakened the positive effect of the specific surface area, resulting in the activation energy of hydrochar to be higher than that of pyrochar.

According to Yang et al. [48], a small $\psi$-value meant that the pore surface area decreased drastically during the entire reaction. The $\psi$-value of RC, P-260, P-300 and $\mathrm{P}-340$ was almost 0 , thus indicating that their pores collapsed noticeably during combustion. Although P-220 had the largest $\psi$-value, its chemical structure was close to that of raw coal and cannot achieve the purpose of low-rank coal reforming. The $\psi$-value of hydrochar was much larger than pyrochar obtained after $220{ }^{\circ} \mathrm{C}$ and $\mathrm{RC}$, indicating that its specific surface area increased during the combustion process. That is, the $\psi$ value was related to the combustibility of the char powder.

\section{Conclusions}

This investigation had focused on the comparison of pyrochar and hydrochar. The experimental data showed that the modification effect of HTC was more obvious than that of pyrolysis in terms of proximate, ultimate, $(\mathrm{O}+\mathrm{H}) / \mathrm{C}$ values and HHV values. Based on the results of FTIR and Raman, it could be concluded that HTC was superior to pyrolysis in terms of removing oxygen-containing functional groups and stabilizing carbon structure. The fitting result of RPM showed that the activation energy of the hydrochar was higher, implying a more stable chemical structure. In addition, the combustibility of hydrochar was better than that of pyrochar at the heating rate of $20{ }^{\circ} \mathrm{C} \cdot \mathrm{min}^{-1}$. Based on the results, it was concluded that upgrading effect of HTC was more intense comparing to pyrolysis. Also, the reactivity of the obtained hydrochar was better.
Acknowledgements This work was supported by the National Natural Science Foundation of China (Nos. 52074029, 1804026). Chuan Wang would like to acknowledge the funding support from Vinnova (dnr: 2017-01327)

\section{References}

1. World Steel Association. Worldsteel short range outlook October 2020: Brussels, Belgium; 2020.

2. Alexander B, Dieter S, Miguel F. Charcoal behaviour by its injection into the modern blast furnace. ISIJ Int. 2010;50:81-8.

3. $\mathrm{Mu} \mathrm{L}, \mathrm{Li} \mathrm{XM}$, Liu XF, et al. Characterization and emission factors of carbonaceous aerosol from coke production in China. Environ Pollut. 2020;268:115768.

4. She Y, Zou C, Liu SW, et al. Combustion and gasification characteristics of low-temperature pyrolytic semi-coke prepared through atmosphere rich in $\mathrm{CH}_{4}$ and $\mathrm{H}_{2}$. Green Process Synth. 2021;10:189-200.

5. Díez MA, Alvarez R, Barriocana C. Coal for metallurgical coke production: predictions of coke quality and future requirements for coke-making. Int J Coal Geol. 2002;50:389-412.

6. Han S, Chen H, Long RY, et al. Peak coal in China: a literature review. Resour Conserv Recycl. 2018;129:293-306.

7. Lv T, Fang MX, Li HX, et al. Pyrolysis of a typical low-rank coal: application and modification of the chemical percolation devolatilization model. RSC Adv. 2021;11:17993-8002.

8. Xie KC. Coal structure and its reactivity. 1st ed. Beijing: Science Press; 2002.

9. Suopajärvi H, Kemppainen A, Haapakangas J, et al. Extensive review of the opportunities to use biomass-based fuels in iron and steelmaking process. J Clean Prod. 2017;148:709-34.

10. Wei RF, Zhang LL, Cang DQ, et al. Current status and potential of biomass utilization in ferrous metallurgical industry. Renew Sust Energy Rev. 2017;68:511-24.

11. Bach QV, Tran KQ, Skreiberg Ø. Combustion kinetics of wettorrefied forest residues using the distributed activation energy model (DAEM). Appl Energy. 2017;185:1059-66.

12. Kenneth B, Joseph C, John G, et al. Occupational safety and health implications of increased coal utilization. Environ Health Perspect. 1979;33:285-302.

13. Chen P. Influence of major emissions from pyrolysis conversion processes of coal on environment and health. Clean Coal Technol. 2001;4:52-9.

14. Bergius F. Production of hydrogen from water and coal from cellulose at high temperatures and pressures. J Soc Chem Ind. 1913;9:462-7.

15. Wang GW, Zhang JL, Lee JY, et al. Hydrothermal carbonization of maize straw for hydrochar production and its injection for blast furnace. Appl Energy. 2020;266:1148-218.

16. Mumme J, Eckervogt L, Pielert J, et al. Hydrothermal charbonization of anaerobically digested maize silage. Bioresour Technol. 2011;102:9255-60.

17. Gao P, Zhou YY, Meng F, et al. Preparation and characterization of hydrochar from waste eucalyptus bark by hydrothermal carbonization. Energy. 2016;97:238-45.

18. Funke A, Ziegler F. Hydrothermal carbonization of biomass: a summary and discussion of chemical mechanisms for process engineering. Biofuels Bioprod Biorg. 2010;4:160-77.

19. Nakajima T, Hasegawa $H$, Takanashi H, et al. Ecotoxicity of effluents from hydrothermal treatment process for low-rank coal. Fuel. 2013;104:36-40.

20. Ganesh K, Parshetti S, Kent H, et al. Chemical, structural and combustion characteristics of carbonaceous products obtained 
by hydrothermal carbonization of palm empty fruit bunches. Bioresour Technol. 2013;135:683-9.

21. Shen YF. A review on hydrothermal carbonization of biomass and plastic wastes to energy products. Biomass Bioenergy. 2020;134:105479.

22. Mäkelä M, Volpe M, Volpe R, et al. Spatially resolved spectral determination of polysaccharides in hydrothermally carbonized biomass. Green Chem. 2018;20:1114-20.

23. Park KY, Lee K, Kim D. Characterized hydrochar of algal biomass for producing solid fuel through hydrothermal carbonization. Bioresour Technol. 2018;258:119-24.

24. Najam US, Saeid B, Ajit KS. Physicochemical, structural and combustion characterization of food waste hydrochar obtained by hydrothermal carbonization. Bioresour Technol. 2018;266:357-63.

25. Zhang XY, Gao B, Zhao SN, et al. Optimization of a "coal-like" pelletization technique based on the sustainable biomass fuel of hydrothermal carbonization of wheat straw. J Clean Prod. 2020;242:1184-226.

26. Wei JT, Song XD, Guo QH, et al. Reactivity, synergy, and kinetics analysis of $\mathrm{CO}_{2}$ co-pyrolysis/co-gasification of biomass after hydrothermal treatment and coal blends. Energy Fuels. 2020;34:294-303.

27. Zhang D, Liu P, Lu X, et al. Upgrading of low rank coal by hydrothermal treatment: coal tar yield during pyrolysis. Fuel Process Technol. 2016;141:117-22.

28. Shi Z, Jin L, Zhou Y, et al. Effect of hydrothermal treatment on structure and liquefaction behavior of Baiyinhua coal. Fuel Process Technol. 2017;167:648-54.

29. Wu J, Liu J, Xu Z, Wang Z, et al. Chemical and structural changes in XiMeng lignite and its carbon migration during hydrothermal dewatering. Fuel. 2015;148:139-44.

30. Akiya N, Savage E. Roles of water for chemical reactions in hightemperature water. Chem Rev. 2002;102:2725-50.

31. Catalina RC, Tobias H, Ariane VS, et al. Pyrolysis vs. hydrothermal carbonization: understanding the effect of biomass structural components and inorganic compounds on the char properties. J Anal Appl Pyrolysis. 2019;140:137-47.

32. Céline H, Florian D, Jonathan T, et al. Comparison of pyrolysis and hydrothermal liquefaction of Chlamydomonas reinhardtii. Growth studies on the recovered hydrothermal aqueous phase. Biomass Bioenergy. 2015;73:23-31.

33. Zhou Y, Li L, Jin LJ, et al. Effect of functional groups on volatile evolution in coal pyrolysis process with in-situ pyrolysis photoionization time-of-flight mass spectrometry. Fuel. 2020;260:116322.

34. Channiwala SA, Parikh PP. A unified correlation for estimating HHV of solid liquid and gaseous fuels. Fuel. 2002;81:1051-63.
35. Zhu GK, Yang L, Gao Y, et al. Characterization and pelletization of cotton stalk hydrochar from HTC and combustion kinetics of pellets by TGA. Fuel. 2019;244:479-91.

36. Ge LC. Basic research on typical low-quality coal upgrading and polv-generation system based on the cascade utilization of coal (doctor thesis). China: Zhejiang University; 2014. (in Chinese).

37. Li KJ, Khanna R, Zhang JL, et al. Comprehensive investigation of various structural features of bituminous coals using advanced analytical techniques. Energy Fuels. 2015;29:7178-89.

38. Li GX, Lu YJ, Glarborg P. Development of a detailed kinetic model for hydrogen oxidation in supercritical $\mathrm{H}_{2} \mathrm{O} / \mathrm{CO}_{2}$ mixtures. Energy Fuels. 2020;34:15379-88.

39. Kocsis L, Herman P, Eke A. The modified Beer-Lambert law revisited. Phys Med Biol. 2006;5:91-8.

40. Jae Y, Kim J, Weon C. Effect of molecular size of lignin on the formation of aromatic hydrocarbon during zeolite catalyzed pyrolysis. Fuel. 2019;240:92-100.

41. Miao ZY, Gao MQ, Wan KJ, et al. Modification of Zhaotong lignite by steam explosion treatment: pore structure and oxygencontaining functional groups. Energy Fuels. 2019;33:4033-40.

42. Yang Z, Lu L, Li JJ, et al. Effect of functional groups on volatile evolution in coal pyrolysis process with in-situ pyrolysis photoionization time-of-flight mass spectrometry. Fuel. 2020;260:116322.

43. Peng B, Zhang HY, Zhang YP. Investigation of the relationship between functional groups evolution and combustion kinetics of microcrystalline cellulose using in situ DRIFTS. Fuel. 2019;248:56-64.

44. Zeng C, Favas G, Wu HW, et al. Effects of pretreatment in steam on the pyrolysis behavior of Loy Yang brown Coal. Energy Fuels. 2005;20:281-6.

45. Zhao RZ, Wu YQ, Huang S, et al. Effect of decomposition of oxygen-containing structures on the conversion of lignite in the presence of hydrogen donor solvent. J Anal Appl Pyrolysis. 2020;154:104743.

46. Sheng CD. Char structure characterised by Raman spectroscopy and its correlations with combustion reactivity. Fuel. 2007;86:2316-24.

47. Peterson E. Reaction of porous solids. AIChE J. 1957;3:442-4.

48. Yang F, Fan XL, Zhou ZJ, et al. Kinetics of coal char gasification with $\mathrm{CO}_{2}$ random pore model. J Fuel Chem Technol. 2006;6:671-6.

49. Bojan J, Nebojša M, Ivana R, et al. Model-free and model-based kinetics of the combustion process of low rank coals with high ash contents using TGA-DTG-DTA-MS and FTIR techniques. Thermochim Acta. 2019;676:178337.

Publisher's Note Springer Nature remains neutral with regard to jurisdictional claims in published maps and institutional affiliations. 